\title{
Vanguardia artística y publicidad comercial en la revista Obras (1931-1936)
}

\author{
Francisco Egaña Casariego \\ Universidad de Valladolid
}

RESUMEN:

A pesar de haber sido una de las publicaciones técnicas más importantes de su época, la revista Obras apenas ha merecido la atención de historiadores, arquitectos e investigadores de la comunicación. Editada en Madrid por la constructora Agroman, y concebida fundamentalmente para visibilizar sus trabajos, desempeñó un importante papel en la difusión del Movimiento Moderno en España, contando para ello con colaboradores en el extranjero. Uno de los aspectos sin duda más interesantes de Obras fue la publicidad que incorporaba en sus páginas, permeable a las corrientes artísticas de vanguardia y gestionada a partir de 1934 por la agencia Stentor. Este artículo analiza esta faceta vanguardista de Obras y rescata del olvido la valiosa obra publicitaria que realizó para la revista el dibujante y pintor valenciano José Espert (1907-1951), quien recurrió con frecuencia a la novedosa técnica del fotomontaje.

PALABRAS CLAVE:

Vanguardia, arte, publicidad, revista Obras

\section{ABSTRACT:}

Although it has been one of the most important technical publications during its epoch,

Obras magazine did not receive the deserving attention by historians, architects and communication researches. Edited in Madrid by the construction company Agromán, in order to highlight its works, Performed an important role in the diffusion of the Modernism Movement in Spain, having collaborators from foreing countries. One of the main aspects of Obras was the advertising in its pages, permeable to artistic vanguard currents and managed since 1934 by Stentor agency. This article analyzes avant-garde perspective by Obras and rescues from oblivion the interesting advertising work accomplished for the magazine by the cartoonist and painter from Valencia, José Espert (1907-1951), who frequently drew upon the novel technique of photomontage.

\section{KEY WORDS:}

Vanguard, art, advertising, magazine Obras 
Introducción: arte y publicidad, una fecunda vinculación histórica

Uno de los aspectos menos tratados de las denominadas vanguardias históricas ha sido el diseño gráfico y publicitario. Algo que llama especialmente la atención si tenemos en cuenta que constituyó una de las facetas más características y definitorias de las vanguardias artísticas. Movidas por el deseo de cerrar la brecha abierta en el siglo XVIII entre el arte y la vida ${ }^{1}$, las vanguardias trataron de sacar el arte de las iglesias, los salones y los museos para acercarlo a las masas ciudadanas mediante la creación de nuevos lenguajes visuales, y contando para ello con un poderoso aliado: la máquina. El diseño de carteles y anuncios comerciales, desde el minúsculo insertado en las páginas de un periódico o revista, a los parpadeantes rótulos de neón de las grandes ciudades o las vallas publicitarias concebidas para ser contempladas desde automóviles en movimiento, atraparon la atención de artistas, movimientos y escuelas. Pero también el diseño de libros, tipografías, folletos, envases y envoltorios. Y es que desde el surgimiento de la moderna publicidad con el cartel litográfico en el último tercio del siglos XIX y hasta la Segunda Guerra Mundial, vanguardia y publicidad marcharon juntas en la exploración de nuevos territorios para el arte y la comunicación visual.

La importancia de los movimientos artísticos en la creación de imágenes comerciales ha resultado determinante, al extremo de haberse afirmado que la moderna publicidad surgió en el contexto de las vanguardias de las primeras décadas del pasado siglo mucho más que en las nacientes agencias de publicidad ${ }^{2}$. La contribución de movimientos como el futurismo y el dadaísmo, pero sobre todo el neoplasticismo, el constructivismo y la Bauhaus al diseño gráfico publicitario resultó fundamental. Especial relevancia adquirió la publicidad como nuevo arte social en el constructivismo ruso, donde el artista Ródchenko y el poeta Mayakovski se asociaron durante algunos años para formar el Constructor publicitario (Reklam Konstruktor), considerado el equipo creativo más importante

FONTÁN JUNCO, Manuel, "La vanguardia aplicada, 1890-1950 (instrucciones de uso)", en La vanguardia aplicada, 1890-1950 (cat. expo., Fundación Juan March), Madrid, 2012, pp. 9-12.

2 PÉREZ GAULI, Juan Carlos, El cuerpo en venta. Relación entre arte y publicidad, Madrid, Cátedra, 2000, p. 13. de la historia ${ }^{3}$. Todos estos movimientos recurrieron no sólo a la ilustración y a la tipografía, sino también a la fotografía y a la combinación de todas estas técnicas de representación para crear imágenes comerciales dotadas de una significación artística.

Pero a pesar de su relevancia para la comprensión cabal de las vanguardias históricas, el diseño gráfıco publicitario y comercial no ha merecido la atención de otras manifestaciones artísticas. Sólo en tiempos recientes lo ha sido, fundamentalmente a través de exposiciones. En este sentido la muestra Art \&t Publicité, celebrada en el Centre Georges Pompidou de París en 1992, marcó un hito importante al mostrar a través de un centenar de obras las complejas y oscilantes relaciones mantenidas entre ambos campos a lo largo de más de un siglo ${ }^{4}$. España no ha sido en esto una excepción. En nuestro país apenas se ha prestado atención a esta faceta de la vanguardia desde el campo de la historia del arte, y muy poca desde la publicidad. Este aspecto no ha sido abordado hasta fechas recientes, fundamentalmente a través de exposiciones celebradas en la Fundación Juan March. A la titulada La vanguardia aplica$d a$ (2012) habría que añadir las muestras Kurt Schwitters: vanguardia y publicidad (2014) y Depero futurista 1913-1950 (2014), dedicadas a dos creadores en cuya obra el arte comercial ocupó un lugar muy destacado. En nuestro país las relaciones entre arte y publicidad apenas han sido objeto de atención en el ámbito académico, siendo el profesor Raúl Eguizábal el que más y mejor ha estudiado estos fructíferos intercambios. A sus libros de referencia Fotografía publicitaria ${ }^{5}$ y El cartel en España hay que añadir los artículos publicados fundamentalmente en la revista Pensar la Publicidad, editada por la Universidad Complutense de Madrid, donde es catedrático del departamento de Publicidad y Comunicación Audiovisual.

Desde hace algún tiempo llevo estudiando la publicidad de vanguardia en las revistas españolas de ingeniería y construcción de los años treinta. Unas revistas técnicas que había

\footnotetext{
EGUIZÁBAL MAZA, Raúl, Historia de la publicidad, Eresma \&t Celeste Ediciones, Madrid, 1998, p.

4 Art \&t Publicité 1890-1990 (cat. expo., Centre Georges Pompidou), Paris, Centre Georges Pompidou, 1990.

5 EGUIZÁBAL MAZA, Raúl, Fotografía publicitaria, Madrid, Cátedra, 2006.

6 EGUIZÁBAL MAZA, Raúl, El cartel en España, Madrid, Cátedra, 2014.
} 
manejado con anterioridad desde la óptica de la historia de la arquitectura ${ }^{7}$, pero que han revelado una dimensión totalmente nueva al ser contempladas desde el prisma del grafismo publicitario. Y es que, junto a anuncios comerciales anodinos y convencionales, afloran en todas ellas -en mayor o menor número- algunos que evidencian un carácter vanguardista. Una buena muestra de ello sería la publicidad de la revista Obras, que no ha sido considerada hasta ahora y que centrará este estudio.

Pero no quisiera pasar a analizar la publicidad de esta revista sin dejar constancia de las dificultades inherentes a esta empresa. Y es que los diferentes centros de documentación conservan colecciones de revistas no sólo incompletas, sino mutiladas, al haber sido desposeídas para su encuadernación de aquellas páginas que centran precisamente nuestra atención: la publicidad. Esta circunstancia aciaga afecta no sólo a los fondos antiguos de las bibliotecas de las Escuelas de Arquitectura e Ingeniería o a los Colegios de Arquitectos, sino también a la Biblioteca Nacional de España, lo que constituye, por lo demás, la prueba más palmaria de la relegación de esta vanguardia.

Una empresa constructora y una revista: Agromán y Obras

La revista Obras, subtitulada "Revista de Construcción”, fue editada por la constructora Agroman. Esta empresa fue creada el 10 de junio de $1928^{8}$ en el contexto político y económico de la dictadura de Primo de Rivera, que se caracterizó antes que nada por su ambiciosa política de obras públicas, lo que justifica que algún historiador haya definido a este periodo como "una era de cemento y carreteras"9. Consolidada la empresa, decidió publicar su propia revista, concebida -y no en último lugar-

Para una síntesis de las revistas españolas de arquitectura de esta época, MOSTEIRO, Javier, "Panorama pelas revistas de arquitectura na Espanha do primeiro terço do século XX", en DÁ MESQUITA, Marieta (coord.), Revistas de Arquitectura: Arquivo(s) da Modernidade, Casal de Cambra, Caleidoscopio, 2011, pp. 28-53.

8 "Octavo cumpleaños de 'AGROMÁN', empresa constructora, S. A.”, en Obras, n. ${ }^{\circ}$ 39, Madrid, 1935, pp. 140-11.

9 BEN-AMI, Shlomo, El cirujano de hierro. La dictadura de Primo de Rivera (1923-1930), Barcelona, Planeta, p. 168. como una manera de dar a conocer sus obras y publicitarse.

Obras apareció en 1931 coincidiendo con el inicio de un ciclo especialmente difícil en la construcción, consecuencia de la brusca interrupción de las obras públicas en los últimos gobiernos de la Monarquía (1930-1931). Además, el advenimiento de la Segunda República y la formación de un gobierno socialista generó desconfianza en los inversores y la fuga de capitales $^{10}$, lo que agravó la crisis en la industria de la construcción y en la economía en general. Esta crisis alcanzó su culmen en 1934, arrojando cifras de desempleo alarmantes, lo que motivó la promulgación de la Ley de paro obrero del año siguiente que revertiría en parte una situación que la guerra iba a truncar. Pero a pesar de la coyuntura adversa que acompañó a la publicación a lo largo de toda su andadura, Agroman realizó durante este periodo obras importantes, entre otras el Salto del Encinarejo sobre el río Jándula (1932), el Metro a los barrios bajos (1932), la pavimentación de La Gran Vía de Madrid (1933), los viaductos de la Ciudad Universitaria (1934) y el puente sobre el río Saler en Cáceres (1935). Entre los técnicos de plantilla figuraron los arquitectos Manuel Martínez Chumillas y Gaspar Blein, y los ingenieros de caminos Carlos Mendoza Jiménez y Carlos Pérez Calle.

La revista editó 50 números -y no 49 como se ha escrito erróneamente ${ }^{11}$ - antes de interrumpir su tirada en 1936 como consecuencia del estallido de la Guerra Civil. Su redactor jefe fue Antonio Botella y tuvo una periodicidad mensual a partir del número cuatro, con entregas que rondaban las 60 páginas y abundante publicidad. Obras editó algunos números monográficos, como los dedicados a la Reforma Interior de Madrid o al Plan Nacional de Obras Hidráulicas. La revista contaba con una sección titulada "Obras de actualidad mundial", que mostraba fotografías de las grandes construcciones de ingeniería - presas, esclusas, puentes, autopistas y rascacielos- realizadas durante ese año, tanto en Europa como en América. Estaba compuesta a dos columnas de texto e incorporaba abundante material fotográfico, contando con la colaboración del pintor y dibujante Antonio Cañabate, que ilustró con sus caricaturas algunos de los

\footnotetext{
10 TUÑON DE LARA, Manuel, "La Segunda República”, en Cuadernos de Historia 16, n. ${ }^{\circ}$ 1, Madrid, 1995, p. 10.

11 BONET, Juan Manuel, Diccionario de las vanguardias en España (1907-1936), Madrid, Alianza, 2007, p. 448.
} 
artículos. Obras fue editada por Artes Gráficas Faure -todo un referente en la época- que imprimió también la revista Viviendas, maquetada por el célebre diseñador polaco Mariano Rawicz. Su administración estableció su sede en la Plaza del Progreso, 5, de Madrid.

En las palabras preliminares del primer número -aparecido en mayo de 1931- se advertía que Obras no era una revista técnica más, pues su finalidad era la divulgación ${ }^{12}$. Sin embargo, en su cuarto número pareció acrecentar sus miras para definirse como "la mejor revista técnica y de divulgación en el campo de la arquitectura y la ingeniería"13. Apenas unos meses después, el ingeniero Sainz de los Terreros la calificaba de "revista de construcción y de arte" ${ }^{14}$, afirmación del todo exagerada por más que publicara él mismo un artículo con el título "El arte en la casa moderna"15. Y es que, frente a otras revistas técnicas coetáneas como Arquitectura o $A C$, los artículos dedicados a artistas plásticos fueron contados, pudiendo destacarse en este sentido el publicado por el redactor de Obras Rafael Pérez Yourieff sobre Vázquez Díaz y el que dedicó el crítico literario Ricardo Gullón a la exposición de Picasso, celebrada en 1936 en el Centro de Exposición e Información Permanente de la Construcción, en Madrid ${ }^{16}$.

Obras prestó atención no sólo a la arquitectura nacional, sino también a las corrientes internacionales de vanguardia, contribuyendo de este modo a la divulgación del Movimiento Moderno en España. Para ello contó con colaboradores extranjeros como el historiador del arte y de la arquitectura berlinés Adolf Behne, contratado en exclusiva para la revista. Discípulo del gran historiador del arte H. Wölfflin, Behne publicó artículos sobre su amigo Walter Gropius y sobre la arquitectura contemporánea en Alemania. Otros cronistas extranjeros fueron Rudolf Fränkel, Dexter Morand, Werner Hegemann, Alfons Leitl -redactor de la revista alemana Die Bauwelt- y Alberto Sartoris, que escribió expresamente para Obras un texto sobre la arquitectura racionalista, tema del que había publicado pocos años antes la gran obra de referencia en

12 Obras, n. ${ }^{\circ}$ 1, Madrid, 1931, p. 1.

3 "Editorial", en Obras, n. ${ }^{\circ}$ 4, Madrid, 1932, s. p.

14 SAINZ DE LOS TERREROS, Luis, "El arte en la casa moderna”, en Obras, n. ${ }^{\circ}$ 8, Madrid, 1932. p. 136.

15 SAINZ DE LOS TERREROS, Luis, "El arte en la casa moderna”, en Obras, n. ${ }^{\circ}$ 8, Madrid, 1932, pp. 136-137.

16 GULLÓN, Ricardo, “Actualidad española de Picasso", en Obras, n. ${ }^{\circ}$ 50, Madrid, 1936, pp. 198-202. este campo ${ }^{17}$. Su redactor jefe, Antonio Botella, publicó entre otros artículos uno sobre el escenógrafo afincado en España Sigfrido Burmann y la necrológica del célebre arquitecto austríaco Adolf Loos. También vieron la luz en la revista algunos textos del arquitecto de la generación del 25 Luis Gutiérrez Soto sobre obras suyas realizadas por Agroman. Obras publicó, además, artículos de los propios técnicos de la constructora. Manuel Martínez Chumillas escribió sobre los arquitectos constructivistas rusos y sobre la arquitectura contemporánea holandesa y francesa. El otro arquitecto de la empresa, Gaspar Blein, lo hizo sobre el Ensanche de Ceuta y sobre la decoración de interiores en Inglaterra. Los estudios sobre arquitectura antigua fueron minoritarios, entre los que cabría señalar el dedicado por Rodríguez Beteta a la arquitectura maya. $\mathrm{Al}$ igual que la revista Arquitectura -órgano de expresión del Colegio de Arquitectos de Madrid-, Obras dio a conocer a través de sus páginas dibujos de arquitectos, entre otros de Joaquín Vaquero Palacios, Luis Moya Blanco y Fernando García Mercadal,

\section{La imagen de la revista: el concurso de portadas}

Si bien la contraportada de Obras permaneció invariable a lo largo de toda su andadura, reproduciendo un anuncio tipográfico de Agroman de diseño muy racional con los nombres del personal técnico de la empresa, no ocurrió lo mismo con la portada. En mayo de 1933 la revista convocó un concurso de portadas. Hasta ese momento su diseño había experimentado con diferentes soluciones, todas ellas de innegable audacia y modernidad. En los primeros números se había optado por la rotulación, a través de unas formas geométricas rectangulares recubiertas de colores planos y filetes negros, que servían de ordenación y estructura a una moderna tipografía dibujada a mano de palo seco con la indicación del título, el número, el mes y el año. Por su orientación vertical y horizontal, su generoso tamaño y el empleo del aerógrafo, la palabra "se convertía en imagen". En su segundo año mediante una amplia ventana abierta en la parte superior derecha que mostraba la fotografía de una arquitectura. Fi-

\footnotetext{
17 Nos referimos al libro Gli Elementi dell'Architettura Razionale, editado en Milán el año 1932
} 
nalmente, en 1933 a través de la superposición de una serie de rectángulos de tamaño creciente y un único color degradados en sus bordes con aerógrafo, técnica que empezaba a utilizarse en los carteles y anuncios para crear la sensación de vibración luminosa ${ }^{18}$.

El reglamento del concurso determinaba que no podría utilizarse para los dibujos sino un único color -además del negro- y contemplaba la posibilidad de recurrir a la fotografía. Los trabajos debían tener 56 centímetros de altura por 48 de anchura. Las bases fijaban el 30 de junio como fecha límite para la entrega de los originales y establecían un único premio de quinientas pesetas ${ }^{19}$, cantidad que equivalía al doble del precio de inserción de un anuncio a plana entera y a una tinta en un número de la revista ${ }^{20}$.

A la convocatoria concurrieron un total de 53 trabajos, algunos de ellos de marcado interés por su enfoque vanguardista. Entre los que recurrieron a la ilustración se hallaba el del dibujante y cartelista valenciano José Espert, del que nos ocuparemos más adelante por ser el autor de algunos de los anuncios más interesantes aparecidos en la revista. Su propuesta mostraba una reinterpretación moderna de una figura clásica colocando una columna toscana sobre su podio ${ }^{21}$. Algunas soluciones recurrieron al dibujo de arquitecturas modernas, como la de Benito Borrachina, que representaba la perspectiva isométrica de una vivienda unifamiliar racionalista con cubierta plana y amplios ventanales corridos ${ }^{22}$. Hubo varias que utilizaron el icono del rascacielos, convertido en paradigma de modernidad en aquellos años y popularizado a través del cine y la fotografía ${ }^{23}$. Entre ellos, el firmado "Fabre Hermanos"

18 Una reproducción facsímil de estos tres modelos de cubierta puede verse en Obras n. ${ }^{\circ}$ 19, Madrid, 1933, p. 177, y Obras, n. ${ }^{\circ} 20$, Madrid, 1933, p. 236.

19 "Concurso de portadas", en Obras, n. ${ }^{\circ}$ 19, Madrid, 1933, p. 177. Estas mismas bases se publicaron en el n. ${ }^{\circ} 20$ de la revista, añadiendo que el plazo de admisión de los trabajos quedaba ampliado hasta el 31 de julio. "Concurso de portadas", en Obras, n. ${ }^{\circ}$ 20, Madrid, 1933, p. 236.

20 “Tarifas de publicidad", en Obras, 17 (1933).

$21 \quad$ Obras, n. ${ }^{\circ} 22$, Madrid, 1933, p. 320.

22 Obras, n. ${ }^{\circ} 22$, Madrid, 1933, p. 317.

23 Sobre la imagen del rascacielos en la publicidad de las revistas técnicas españolas de la época, véase EGAÑA CASARIEGO, Francisco, "La metrópoli soñada. La imagen del rascacielos en la publicidad de las revistas españolas de arquitectura y construcción de los años treinta”, en VII Jornadas Internacionales Arte y Ciudad, Madrid, Universidad Complutense, 2016, pp. 225-234. Bajo este mismo título -y en colaboración con Susana Feito- comisarié una exposición en la Biblioteca de la resulta el más interesante ${ }^{24}$ [[fig. 1]. Mostraba unos rascacielos contemplados desde el interior de otro edificio a través de una ventana, siguiendo en esto modelos fotográficos americanos conocidos entre nuestros ilustradores por su reproducción en algunas revistas técnicas españolas ${ }^{25}$. En primer término, sobre el alféizar de la ventana y perfilándose contra el skyline del fondo, apoyaba un cactus, planta muy característica del art déco que se puso de moda en nuestro país desde finales de la década de los veinte ${ }^{26}$. Siguiendo las bases de la convocatoria, la propuesta se completaba

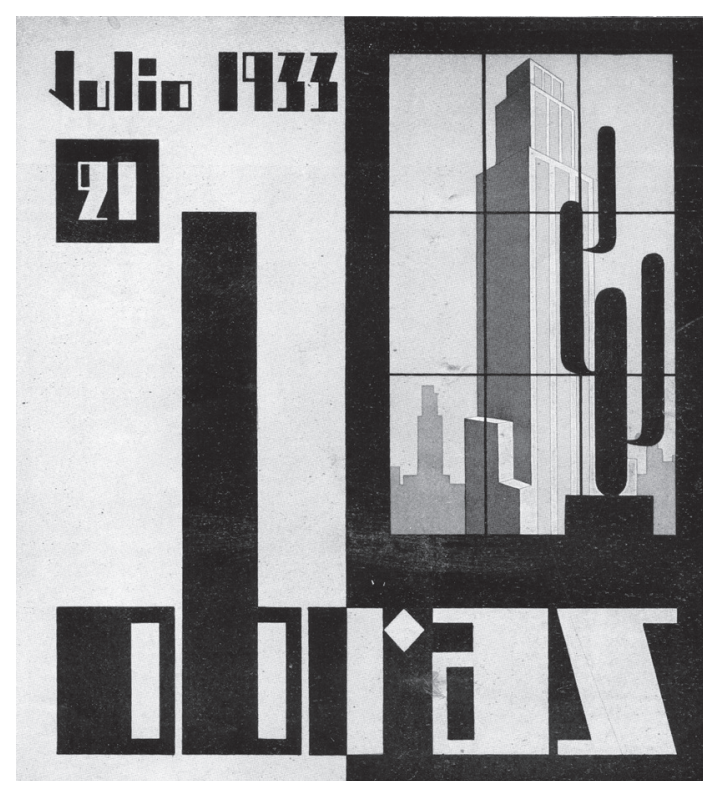

Fig. 1. Fabre Hermanos. Diseño para el concurso de portadas convocado por la revista Obras. Obras, 22 (1933).

Escuela de Arquitectura de Madrid (ETSAM) que pudo contemplarse entre los meses de enero y abril de 2016. Para una reseña crítica de esta exposición, MOSTEIRO, Javier, “Exposición La metrópoli soñada. La imagen del rascacielos en la publicidad de las revistas españolas de arquitectura y construcción de los años treinta”, en EGA: Revista de Expresión Gráfica Arquitectónica, n. ${ }^{\circ}$ 32, Valencia, 2018, p. 15.

$24 \quad$ Obras, n. ${ }^{\circ} 22$, Madrid, 1933, p. 319.

25 La propia revista Obras publicó en su n. ${ }^{0} 16$ de 1933 una fotografía de este tipo, con el siguiente pie de foto: "Una vista del barrio bancario de New York tomada desde un rascacielos". Obras, n. ${ }^{\circ}$ 16, Madrid, 1933, p. 57.

26 Esta planta comenzó a imponerse en España a partir de 1928, coincidiendo con la aparición de las primeras sillas de tubo de acero. FOXÁ, Agustín de, Madrid, de Corte a checa, Ciudadela, Madrid, 2006, p. 140. Sobre el furor vanguardista por esta familia vegetal, SATUÉ, Enric, "Hasta el cactus se hace vanguardia, y por eso cotidiano", en Los años del diseño. La década republicana, Madrid, Turner, 2003, pp. 37-40. 
con la indicación del título de la revista, el número, el mes y el año con una letra dibujada de palo seco, reflejo del diseño gráfico de la época marcado por la geometrización del cubismo y sus derivados. Acogiéndose al reglamento del concurso, hubo trabajos que se basaron en la fotografía a través de una solución ya experimentada a lo largo de 1932 en la revista: la ventana con la fotografía de una arquitectura. Entre estas resultaba particularmente sugerente la que mostraba un sencillo bodegón compuesto por una llana de albañil y una plomada, siguiendo planteamientos fotográficos cercanos a la Nueva Objetividad ${ }^{27}$.

El jurado del concurso estuvo formado por el redactor jefe de la revista, Antonio Botella, el arquitecto Pedro Muguruza y el escritor y crítico de arte Manuel Abril, que dos años después alcanzaría celebridad por su ensayo De la naturaleza al espiritu, dedicado a la pintura española contemporánea y galardonado con el Premio Nacional de Literatura. El acta, fechada el 15 de agosto de $1933^{28}$, otorgaba por unanimidad el primer premio a la propuesta presentada por el dibujante Guillermo Orive. Este recurrió a la combinación del fragmento de la planta de una vivienda con una ventana abierta en el ángulo superior derecho que dejaba ver un fotomontaje a partir de fragmentos de fotografías de fachadas arquitectónicas y la preceptiva rotulación, con un tipo sin remates muy elegante ${ }^{29}$ [fig. 2]. El jurado ensalzaba en el trabajo ganador la "adecuada proporción entre la magnitud del letrero principal 'Obras' y la dimensión total de la portada", así como la legibilidad de su tipografía. Valoraba igualmente el dictamen la circunstancia de que los elementos integrantes de la portada fueran de fácil renovación - tanto en asunto como en color- de manera que permitiera una variedad constante para los doce números en que se habría de repetir el tema fundamental ${ }^{30}$. Y así fue, en efecto, pues a partir de este momento la cubierta de los sucesivos números varió únicamente en el color de fondo y la fotografía de la ventana, por lo general una obra de arquitectura o ingeniería relacionada

27 Esta propuesta estaba firmado por Alberto Pereda, Ignacio Saavedra y Antonio Jarillo. Obras, n. ${ }^{\circ}$ 22, Madrid, 1933, p. 321.

28 El acta del jurado, junto con la reproducción de algunos de los trabajos presentados, puede verse en Obras, n. ${ }^{\circ}$ 22, Madrid, 1933, pp. 315-323.

29 Véase Obras, n. ${ }^{\circ}$ 22, Madrid, 1933, p. 323.

30 Obras, n. ${ }^{\circ}$ 22, Madrid, 1933, pp. 315-319.

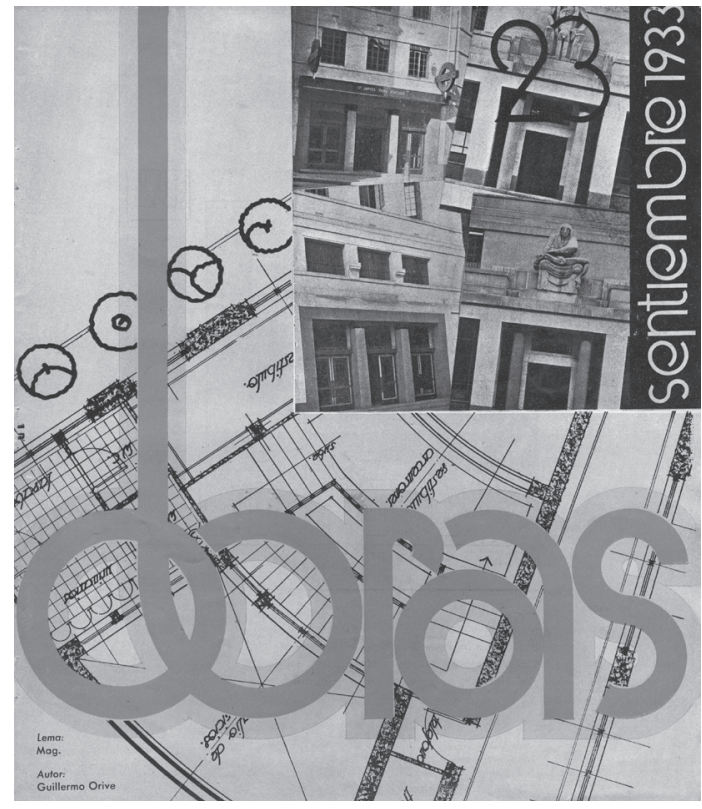

Fig. 2. Guillermo Orive. Diseño ganador del concurso de portadas convocado por la revista Obras. Obras, 22 (1933).

con los contenidos de ese número de la revista. Por lo demás, el formato ligeramente cuadrado $-28 \times 24 \mathrm{~cm}$ - se mantuvo invariable desde el primer hasta el último número, aparecido en el mes junio de 1936.

\section{La publicidad en Obras}

Uno de los objetivos fundamentales de la revista fue publicitar la propia empresa constructora y sus obras. En este sentido, la publicación daba a conocer en cada uno de sus números una obra realizada por Agroman. Pero la revista publicó también abundante publicidad vinculada a otras firmas comerciales. Se trataba de publicidad dedicada casi exclusivamente a productos vinculados con la construcción como ladrillos, cementos, hierros, impermeabilizantes o placas de uralita. A partir de 1934 la agencia Stentor -creada ese mismo año en Madrid- actuó como administradora exclusiva de la publicidad de Obras. Ella misma se publicitaba en sus páginas a través de un anuncio tipográfico a plana entera con una ordenación geométrica y una disposición oblicua de claras resonancias bauhausianas $^{31}$.

Este anuncio se reprodujo en todos los números de la revista a partir del $n .^{\circ} 28$, correspondiente a marzo de 1934. 
Agroman lanzó varias campañas publicitarias a través de su revista. Una de ellas, la de inyecciones automáticas de cemento para la consolidación de cimientos y la reparación de grietas en los edificios. En este caso se recurrió a la ilustración dibujada, a través de edificios atravesados por inyecciones y acompañados por el eslogan "con una inyección... fuera de peligro". Uno de ellos muestra el detalle de un rascacielos ${ }^{32}$ [fig. 3]. Su violento encuadre, similar a un contrapicado fotográfico, unido a las agujas que lo penetran a modo de líneas de fuerza y a los extraños reflejos de un cielo que cabe intuir nocturno le confieren un aire futurista. En la parte inferior del anuncio -publicado siempre a plana entera- aparece el nombre de la empresa en una tipografía en caja alta semejante a la Bifur, creada en 1929 por el gran cartelista de entreguerras Cassandre y caracterizada por la sustitución de fragmentos de letras por zonas sombreadas que completaban la silueta $^{33}$. Otro anuncio de inyecciones de cemento Agroman representa un edificio vertical resquebrajado y con una gigantesca jeringuilla clavada en su estructura ${ }^{34}$. Este anuncio aparece firmado por el dibujante valenciano José Espert, que alcanzó celebridad con su cartel de la paleta Agromán, publicado también en esta revista ${ }^{35}$.

El recurso a la ilustración dibujada aparece en otra de las campañas de Agroman, en este caso en algunos anuncios para la construcción de casas individuales a precios económicos. Uno de ellos ofrece la particularidad de mostrar como prototipo de construcción una sencilla vivienda con cubierta en terraza y ventanas corridas, de clara ascendencia racionalista ${ }^{36}$. La autoría del croquis se debe al arquitecto de la propia Agroman, Manuel Martínez Chumillas, vinculado a la nueva arquitectura ${ }^{37}$. El dibujo se acompañaba de la planta del edificio y de

32 Obras, n. ${ }^{\circ} 15$ (1933). Este anuncio apareció regularmente en la revista entre los años 1933 y 1934.

33 SATUÉ, Enric, Arte en la tipografía y tipografía en el arte. Compendio de tipografía artística, Madrid, 2007, pp. 120-122.

34 Obras, núms, 30-35 (1934); 36-44 (1935) y 45-50 (1936).

35 Véase Botella, Antonio, "Concurso de carteles publicitarios de la Unión de Dibujantes", en Obras, n. ${ }^{\circ}$ 16, Madrid, 1933, p. 69. El cartel de la paleta Agromán apareció por vez primera como anuncio en el n. ${ }^{\circ} 16$ de Obras (1933), y dos años después en la revista Nuevas Formas, n. ${ }^{\circ}$ 6, Madrid, 1935.

36 Obras, núms. 12 y 13 (1932).

37 MARTÍNEZ CHUMILLAS, Manuel, "Una realización", en Obras, n. ${ }^{\circ}$ 14, Madrid, 1932, pp. 309-311.

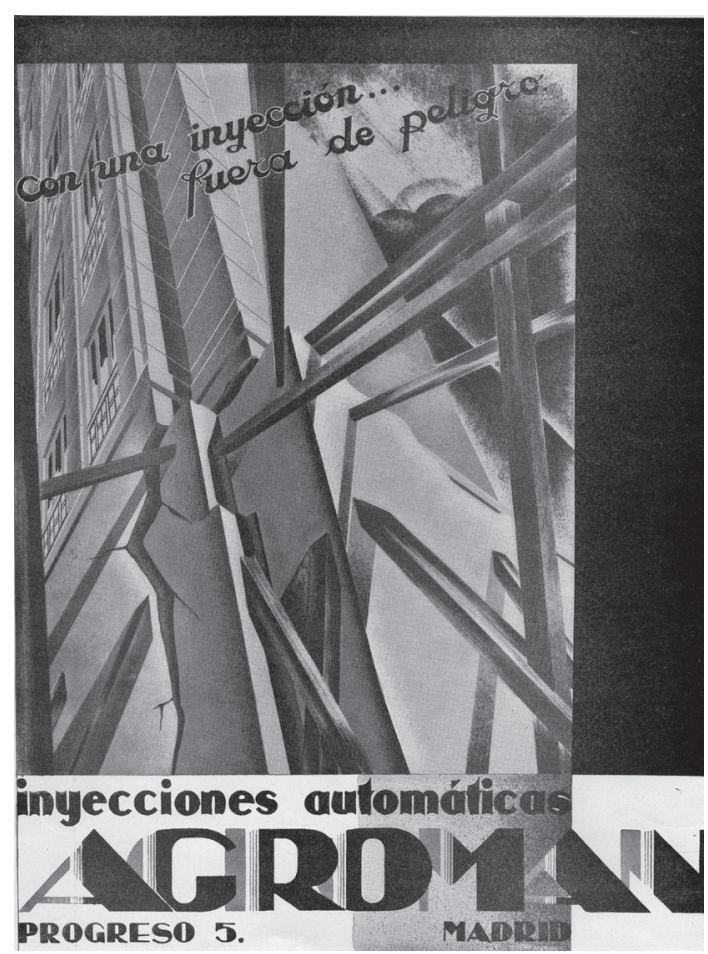

Fig. 3. Anónimo. Anuncio de inyecciones automáticas Agromán. Obras, 15 (1933).

una breve memoria, con una ordenación de conjunto muy racional y geométrica.

Pero la campaña publicitaria más importante de Agroman fue sin duda la de los impermeabilizantes de la empresa Tecnicrom S. A., vinculada a la constructora y cuya oficina de asesoramiento técnico se ubicaba en la sede de Agroman de la calle del Progreso. Esta campaña se concretó en una serie de anuncios en los que recurrió fundamentalmente a la técnica de la fotografía, cuyo empleo con fines comerciales y publicitarios constituía una nota de modernidad, al haber sido introducida en este campo apenas una década antes por el constructivista ruso El Lissitzky ${ }^{38}$. Algunos de estos anuncios -y sin duda los más interesantes- emplearon el fotomontaje. Esta técnica, que constituía una variante fotográfica del collage cubista, había surgido hacia 1919 de la mano de los dadaístas berlineses John Heartfield y Georg Grosz ${ }^{39}$. De la crítica política y social pasó pronto al cartel cinematográfico y a la publicidad comercial a

38 NISBET, Peter, "Lissitzky y la fotografía", en El Lissitzky (1850-1941). Arquitecto, pintor, fotógrafo, tipógrafo (cat. expo., Fundación Caja de Pensiones), Madrid, 1990, pp. 66-69.

39 WESCHER, Herta, La historia del collage. Del cubismo a la actualidad, Barcelona, Gustavo Gili, 1976, pp. 108-120. 
través del constructivismo ruso y la Bauhaus alemana ${ }^{40}$. Estos movimientos de vanguardia descubrieron su enorme potencial en esos campos no sólo desde un punto de vista plástico, sino también comunicativo. En el caso del cartel cinematográfico permitía reunir en el mismo espacio imágenes que el cine yuxtaponía en el tiempo ${ }^{41}$. Esta solución se mostraba igualmente idónea en el caso de la publicidad relacionada con la construcción, al permitir confrontar sobre un mismo plano obras y construcciones alejadas en el espacio y en el tiempo.

La campaña del impermeabilizante Bestoseal incluyó toda una serie de fotomontajes que publicitaban el producto a través de la combinación y yuxtaposición de fragmentos de fotografías de fachadas y obras, que revelaban una extraordinaria modernidad y audacia comunicativa. El primero en aparecer mostraba fragmentos de planos, croquis y fotografías de cubiertas y muros de edificios, depósitos, presas, canales y tuberías para mostrar la versatilidad de este producto aplicable sobre todo tipo de construcciones y materiales ${ }^{42}$. Uno de los más logrados mostraba el montaje de fragmentos de fotografías parciales de algunos edificios de la Ciudad Universitaria de Madrid -terminados o en construcción- como la Facultad de Ciencias y la Facultad de Odontología, combinados con maquetas y plantas de edificios ${ }^{43}$ [fig. 4]. Otro superponía fotografías de algunos edificios de la capital impermeabilizados con Bestoseal, como el Metropolitano, el teatro-cine Coliseum y el edificio de Pescaderías Coruñesas de la calle Recoletos ${ }^{44}$ [fig. 5]. Estos tres fotomontajes -reproducidos a plana entera- exhiben la firma de José Espert y fueron publicados también en otras revistas técnicas de la época, como Hormigón y Acero y Revista de Obras Públicas.

Esta campaña publicitaria de impermeabilizantes emprendida por Agroman a través de la agencia Stentor recurrió en algunos de sus anuncios a la fotografía como medio de representación, y en menor medida a la ilustración. De indudable ascendencia rusa puede calificarse

40 BAÑUELOS CAPISTRÁN, Jacob, Fotomontaje, Madrid, Cátedra, 2008, pp. 83-168.

${ }^{41}$ LECLANCHE-BOULE, C., Constructivismo en la URSS. Tipografías y fotomontajes, Valencia, Campgráfic, 2003, p. 23.

42 Obras, n. 27 (1934).

43 Obras, núms. 28-30 (1934).

44 Obras, núms, 37-44 (1935), y 45-48 (1936); Revista de Obras Públicas, n. ${ }^{\circ}$ 18, Madrid, 1935. uno que muestra la fotografía parcial de un edificio desde un punto bajo y diagonal. En la parte superior aparece un círculo rojo -a la manera de globo o "bocadillo" de un cómic- con el texto

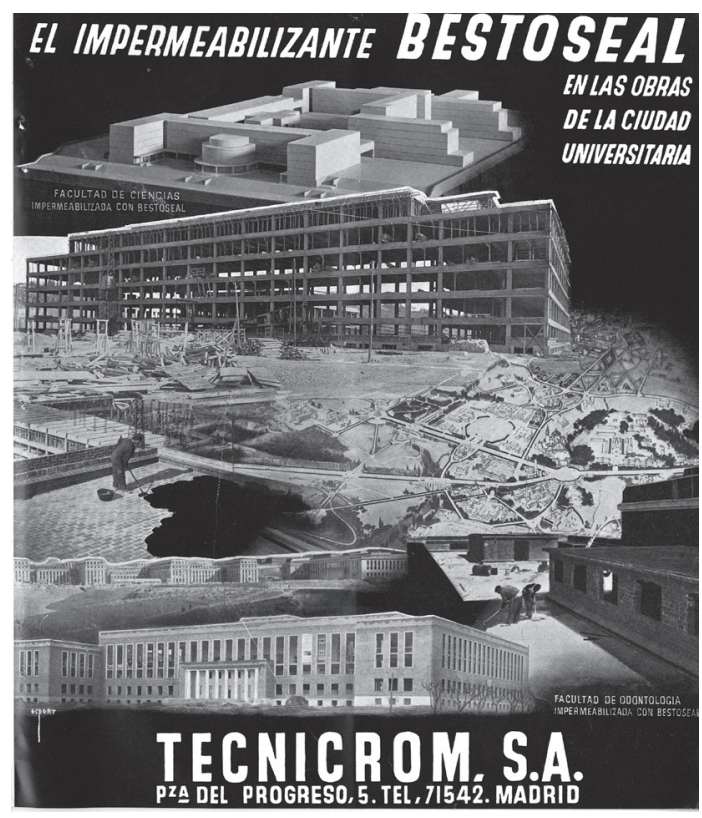

Fig. 4. José Espert. Anuncio de Impermeabilizante Bestoseal. Obras, 28 (1934).

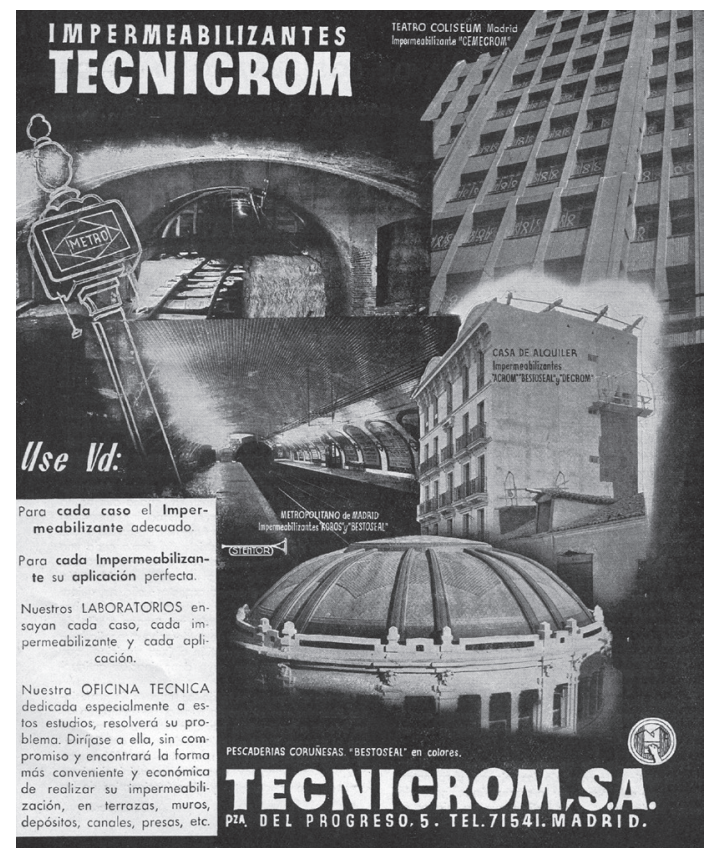

Fig. 5. José Espert. Anuncio de Impermeabilizante Tecnicrom, S. A. Obras, 37 (1935).

"el punto vulnerable" y una flecha que sale de él indicando ese lugar en la cubierta en terraza 
de este moderno edificio. En la zona inferior, un texto con algunos signos de exclamación que recuerdan el tono imperativo de los eslóganes del Constructor publicitario Ródchenko-Mayakovs$\mathrm{ki}^{45}$. Cabría señalar que para este anuncio fue reutilizada una fotografía reproducida escasos meses antes en esta misma revista para ilustrar un artículo sobre una colonia de casas baratas levantada en Bagneux, París ${ }^{46}$.

Otro anuncio, en este caso del impermeabilizante Mastertex, muestra una fotografía del nuevo teatro-cine Coliseum de Madrid, obra de los arquitectos Pedro Muguruza y Casto Fernández Shaw. En su violentísimo contrapicado denota el conocimiento de la fotografía del constructivista ruso Aleksandr Ródchenko, que desde la década anterior venía reivindicando puntos de vista insólitos y exagerados para incrementar el interés de las fotografías ${ }^{47}$. Por lo demás, en la estructura compositiva del anuncio, con la rigurosa ordenación geométrica de la fotografía, la tipografía y los espacios en blanco puede reconocerse -como en tantos otros anuncios publicados en esta revista- la influencia de la corriente constructivista que animó por aquellos años el panorama plástico internacional de vanguardia. Uno de los principales propagadores de aquel lenguaje abstracto geométrico fue el neoplasticista holandés Theo van Doesburg, fundador junto al pintor Piet Mondrian de la revista De Stijl. Van Doesburg ejerció una gran influencia en Europa al extrapolar las teorías y el lenguaje universal de líneas y ángulos rectos de la pintura de Mondrian a la arquitectura, la tipografía y el diseño gráfico. Las ideas y la obra del arquitecto y pintor van Doesburg eran conocidas en nuestro país a través de la publicación de algunos artículos suyos en la revista Arquitectura ${ }^{48}$, y de su estancia en España en 1930 con motivo de su conferencia en la Residencia de Estudiantes de Madrid ${ }^{49}$.

$\overline{45 \quad \text { Obras, n. }{ }^{\circ} 24}$ (1933).

46 "Arquitectura francesa. Casas baratas", en Obras, n. ${ }^{\circ}$ 19, Madrid, 1933, pp. 194-200. La fotografía aparece reproducida en la página 194.

47 WEISS, Evelyn, "La vanguardia rusa: 1910-1930", en Vanguardia rusa 1910-1930. Museo y colección Ludwig, cat. expo., Madrid, Fundación Juan March, 1985, p. 143.

48 Arquitectura, n. ${ }^{\circ}$ 96, Madrid, 1927, pp. 143-149; Arquitectura, n. ${ }^{\circ}$ 98, Madrid, 1927, pp. 213-220; Arquitectura, n. ${ }^{\circ}$ 105, Madrid, 1928, pp. 16-21; Arquitectura, n. ${ }^{\circ} 111$, Madrid, 1928, pp. 220-225.

49 "Conferencia del arquitecto Theo van Doesburg (1930)”, en La Construcción Moderna, n. ${ }^{\circ}$ 11, Madrid,
A Espert se deben también una serie de anuncios que mostraban fotografías de obras realizadas por la constructora Agroman Entre ellos, dos de grandes presas acompañados del lema de la empresa: "en el plazo prometido, en el precio convenido". Un fotomontaje, en este caso sin firmar -aunque atribuible también a Espert- mostraba aspectos parciales del Casa Blanca Dancing Café, el moderno local de ocio del arquitecto de la generación del 25 Luis Gutiérrez Soto, que aparecían junto al lema de Agroman $^{50}$.

Pero la revista Obras publicó también anuncios comerciales de empresas de ascensores, contratistas, máquinas de escribir, ventanas metálicas, hierros, maderas, etc., que recurrieron para ello a todas las técnicas gráficas, como la tipografía, la imagen dibujada o pintada y la fotografía. Especial interés reviste un anuncio de ascensores de la empresa Boetticher y Navarro aparecido por primera vez en 1932, que lleva el sello de la agencia Publicitas [fig. 6]. Muestra el dibujo de un ascensor desde un punto de vista elevado y evocado a través de unas líneas muy escuetas. El afán de dinamismo - tan característico del futurismo- queda patente en las diagonales de las guías y cables de sujección y en la espiral que, partiendo de la cabina, remata en una tipografía tridimensional creciente con el nombre de la empresa fabricante de ascensores ${ }^{51}$.

Entre los que recurrieron a la ilustración cabría destacar, igualmente, el firmado por el conocido fotógrafo y dibujante catalán José Masana para los tubos para desagüe de la firma Rocalla $^{52}$. También dos anuncios -en este caso anónimos- del fabricante de ventanas metálicas García-Nieto, que había construido las de muchos de los edificios de la Ciudad Universitaria. Uno de ellos recurría a una figura geométrica de adscripción cubista inserta en una ventana ${ }^{53}$, y el otro al dibujo de un edificio moderno de clara influencia expresionista ${ }^{54}$. A este grupo pertenecerían otros dos -igualmente

1930, p. 158. Además de van Doesburg, y gracias a los contactos establecidos en Europa por el arquitecto Fernando García Mercadal, vinieron también a Madrid para conferenciar en la Residencia de Estudiantes Erich Mendelsohn, Walter Gropius y Le Corbusier.

50 Obras, núms. 29, 31, 34 (1934); 45, 46 y 49 (1936).

Obras, núms. 5 y 6 (1932).

52 Obras, núms. 20, 22, 25 (1933); 26-30 (1934).

53 Obras, núms. 33-35 (1934); 36-44 (1935); 45, 48-50 (1936).

54 Obras, núms. 28, 30 y 32 (1934). 


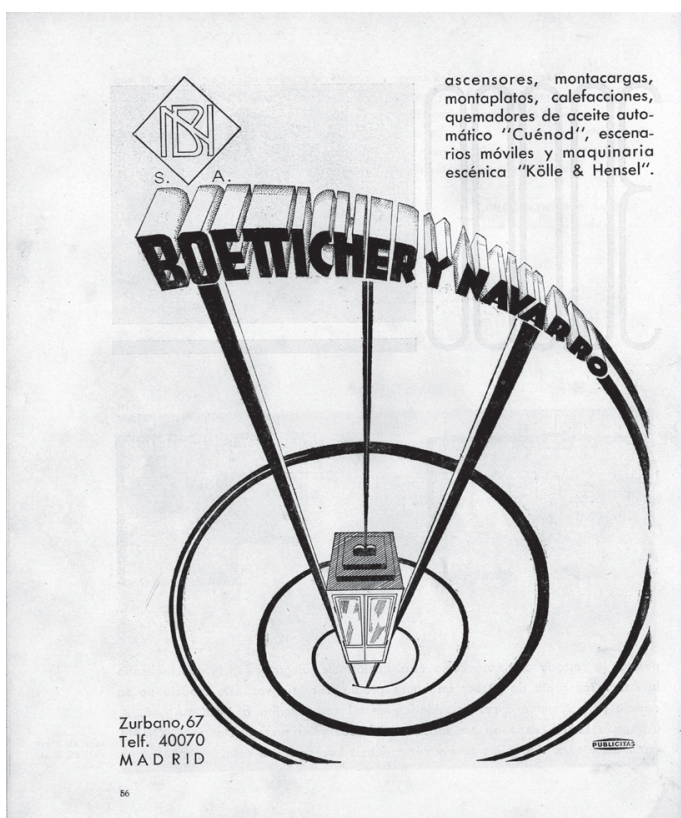

Fig. 6. Anónimo. Anuncio de ascensores Boetticher y Navarro. Obras, 5 (1932).

anónimos- de la firma de máquinas de escribir Hispano Olivetti. El primero de ellos denota la influencia del constructivismo ruso, reconocible en el tema de la fábrica con su chimenea humeante ${ }^{55}$; el otro, resuelto mediante la combinación del fotomontaje y la ilustración, muestra en primer término una figura humana de ascendencia cubista y por fondo un fotomontaje de fragmentos fotográficos del interior de una fábrica con sus trabajadores ${ }^{56}$. Tanto en los anuncios que recurren a la fotografía, la tipografía o la ilustración -como en los que combinan algunas de ellas- se advierte en la mayoría de ellos una ordenación mondrianesca a través de una fuerte geometrización.

Los anuncios tipográficos resultan los más numerosos en la revista y denotan el conocimiento de la importante experimentación llevada a cabo en este campo por las vanguardias de los años veinte y treinta ${ }^{57}$. La referencia neoplasticista, con su inconfundible lenguaje de planos, líneas y ángulos rectos, resulta muy explícita en la estructura compositiva de muchos anuncios, como los de maderas Adrián Piera $^{58}$ o el de las ventanas metálicas Hope y

\footnotetext{
55 Obras, n. ${ }^{\circ} 18$ (1933).

56 Obras, n. ${ }^{\circ} 45$ (1936)

57 Sobre la tipografía en España durante la Segunda República, CÓRDOBA BURKE, Patricia, La vanguardia tipográfica truncada, Valencia, Campgráfic, 2008.

58 Obras, núms. 20, 22, 25 (1933); 26-30, 32 (1934).
}

cubiertas de cristal Eclipse, S. A. ${ }^{59}$ [fig. 7]. En otros, la ruptura con la alineación tradicional del texto llevada a cabo por el futurista $\mathrm{Ma}-$ rinetti ${ }^{60}$, para disponer las palabras de forma totalmente libre, nueva y dinámica, siguiendo una ordenación circular, vertical, horizontal, diagonal, etc., así como el recurso a la caja baja de origen bauhausiano. En este último sentido habría que destacar la serie de anuncios de talleres de cerrajería Alonso Sancho, los del almacén de maderas José Torres y los de lubricantes, correas y maquinaria Enrique Miret Espoy, que recurrieron al alfabeto en minúscula $\mathrm{y}$ al empleo de bandas, puntos y ordenaciones racionales buscando la mayor legibilidad posible. El recurso a la tipografía resultó una constante en la publicidad de la empresa contratista de derribos, vaciados y transportes José Vega, que llevó a cabo importantes trabajos durante estos años, como el vaciado de los edificios de la Telefónica y $A B C$ y el transporte de la tierra para las obras del metropolitano. Se trata de anuncios en los que se emplean letras de palo seco y composiciones geométricas, ordenadas muchas veces a través del empleo de bandas,

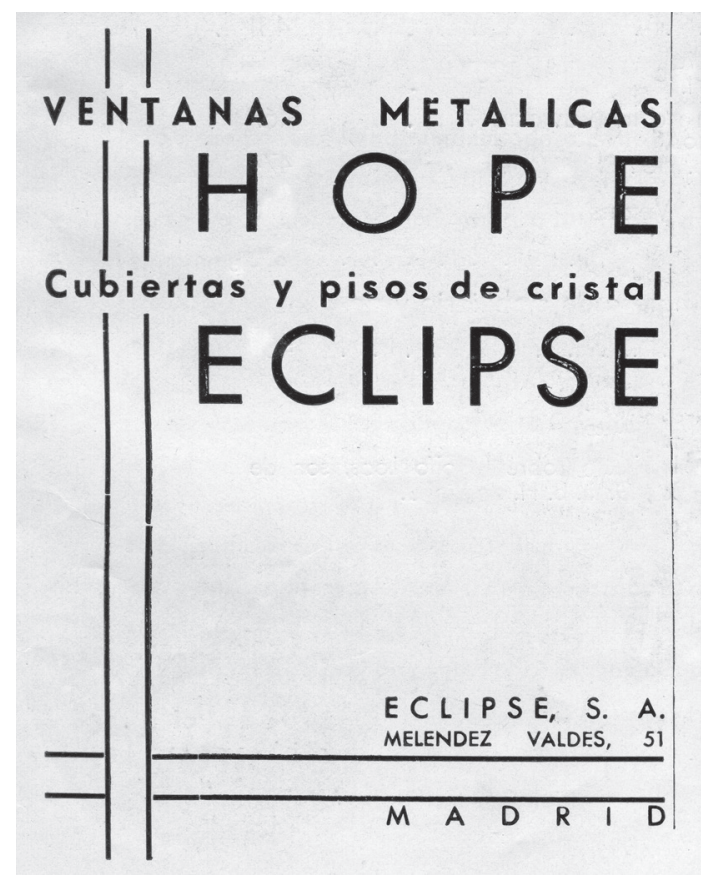

Fig. 7. Anónimo. Anuncio de Ventanas metálicas Hope y Cubiertas y pisos de cristal Eclipse. Obras, 25 (1933).

Obras, núms. 25 (1933); 26 (1934).

60 SCUDIERO, Mauricio, "Vanguardia y tipografía: una lectura transversal", en La vanguardia aplicada (18901950), cat. expo., Fundación Juan March, Madrid, 2012, pp. 164-169. 
filetes y puntos. Mención especial dentro de la publicidad de la empresa contratista de José Vega merece nuevamente un fotomontaje de José Espert, que muestra la superposición de las fotografías de tres camiones ${ }^{61}$. El empleo de esta moderna técnica, junto a la ordenación geométrica del texto y el empleo de una flecha para enfatizar el mensaje, nos remiten una vez más al constructivismo ruso, que junto con el neoplasticismo holandés y la Bauhaus alemana constituyeron los referentes fundamentales del diseño gráfico de vanguardia durante los años finales de la Segunda República ${ }^{62}$.

Un capítulo aparte en la publicidad de la revista -y de indudable originalidad- lo constituyen los cuentos y relatos con tema de construcción escritos expresamente para Obras, e ilustrados con un fino humorismo. Entre los redactores de los textos figuran escritores y periodistas de la importancia de Wenceslao Fernández Flórez, Manuel Abril, Tirso Medina, Antonio Casero y Barranco, Federico Ruiz Morcuende o Nicolás González Ruiz. Como ilustradores de estos relatos aparecen, entre otros, los dibujantes y humoristas Antonio Orbegozo, Salvador Bartolozzi, Antonio Cañabate, Juan Esplandiú y Emilio Ferrer. Por destacar tan sólo alguno de estos relatos, podría señalarse el de Manuel Abril titulado "Loa y honrada lección de los ferrocarriles del subsuelo"63, ilustrado por Esplandiú, y el de Tirso de Medina, "Patología de la construcción” ${ }^{64}$, con ilustraciones de Orbegozo [fig 8]. En ellos se reconocen alusiones muy claras a las obras del Metropolitano realizadas por la constructora y a las inyecciones de cemento Agromán.

\section{Conclusión}

A pesar de la escasa atención que ha merecido hasta la fecha entre arquitectos e historiadores del arte y de la comunicación, Obras constituyó una de las revistas técnicas españo-

\footnotetext{
61 Obras, núms. 25 (1933); 26-30, 32-35 (1934); 36-44 (1935); 45, 46, 48-50 (1936).

62 Para una panorámica del diseño gráfico de estos años, SATUÉ, Enric, Los años del diseño. La década republicana, Madrid, Turner, 2003.

63 ABRIL, Manuel, "Loa y honrada lección de los ferrocarriles del subsuelo", en Obras, n. ${ }^{\circ}$ 16, Madrid, 1933, pp. 70-72.

64 MEDINA, Tirso (Fernando Meana Medina), "Patología de la construcción”, en Obras, n. ${ }^{\circ}$ 17, Madrid, 1933, pp. 102-104.
}

las más importantes de los años treinta. Años en los que, a pesar de la gravísima crisis que afectó al sector de la construcción -y que estuvo en algún momento al borde de colapsarlotuvo lugar una auténtica floración de revistas de arquitectura y construcción magníficamente editadas como Cortijos y Rascacielos (1930), AC (1931), INGAR (1932), Viviendas (1932), Hormigón y Acero (1934), RE-CO (1935) o Nuevas Formas (1934). Estas revistas incorporaban, además, una publicidad de elevado interés plástico que constituía algo nada habitual en aquella época.

Como órgano de expresión de Agroman, la revista surgió para visibilizar las obras realizadas por la constructora y posicionar su imagen de marca. Pero Obras cumplió también una importante función en la difusión del Movimiento Moderno en España, dando a conocer la nueva arquitectura centroeuropea a través de artículos firmados por colaboradores nacionales o extranjeros y reproduciendo obras de destacados arquitectos como Erich Mendelsohn, Hans Poelzig, André Lurçat o Le Corbusier.

Uno de los aspectos sin duda más interesantes de la revista reside en su publicidad, gestionada a partir de 1934 por la agencia Stentor y permeable a las corrientes artísticas de vanguardia de la época. Entre los movimientos que más influyeron en el grafismo publicitario de la revista se hallan las corrientes abstractas geométricas de los años veinte, esto es, neoplasticismo, constructivismo y Bauhaus. Un hecho que contrasta vivamente con la pintura que se hacía en la España de aquellos años, desarrollada de espaldas totalmente a la abstracción y dominada desde finales de los años veinte por el surrealismo ${ }^{65}$.

Si bien se trató en su mayor parte de una publicidad anónima, este estudio ha sacado a la luz un amplio conjunto de anuncios del dibujante, pintor y cartelista valenciano José Espert (1907-1951). Entre todos ellos, los más interesantes sin duda los fotomontajes que realizó para la campaña de impermeabilizantes de Agroman. Su carácter innovador y su calidad plástica obligan a redimensionar la figura de José Espert y a considerarle como uno de los

\footnotetext{
65 CALVO SERRALLER, Francisco, "Sísmicos ismos", en Istmos. Vanguardia española 1915-1936 (cat. expo. Fundación Caja Madrid), Madrid, Turner, 1998, p. 35. Para una visión general del arte en este periodo, BRIHUEGA, Jaime, La vanguardia y la República, Madrid, Cátedra, 1982
} 
pioneros en esta técnica en nuestro país junto al vasco Nicolás de Lekuona y al también valenciano y amigo suyo, Josep Renau, considerado hasta ahora "prácticamente su inventor en España" ${ }^{66}$. Espert era conocido por sus carteles para el Círculo de Bellas Artes ${ }^{67}$, su trabajo como dibujante publicitario para la agencia Publicitas y su cartel de la paleta Agromán ${ }^{68}$. También por sus carteles de guerra para el bando republicano realizados antes de su exilio mexicano. Pero nadie hasta ahora había reparado en esta magnífica serie de fotomontajes publicitarios para las agencias Publicitas y Stentor, que enriquecen el catálogo de su obra y le sitúan en un lugar destacado en historia de la publicidad española, tanto por la cantidad de campañas como especialmente por la calidad artística y la modernidad de las mismas.

El estudio de Obras -así como el de otras revistas técnicas de la época- desvela la existencia de un grafismo publicitario de vanguardia durante los años de la Segunda República, que parece ensanchar la denominada por el historiador José Carlos Mainer "Edad de Plata" de la cultura española con la consideración de esta faceta plástica. El hecho de que esta vanguardia aparezca en las revistas técnicas no parece algo casual, y vendría a confirmar nuestra tesis de que la publicidad aparecida en las revistas técnicas españolas de la época constituyó una publicidad avanzada y permeable a las corrientes artísticas de vanguardia, como correspondía, por lo demás, al perfil sociocultural de sus principales destinatarios: arquitectos, ingenieros y contratistas de obras. En todos los casos, colectivos profesionales procedentes de las capas altas y mejor formadas de la sociedad. En el caso particular de los arquitectos, además, un colectivo profesional en cuya formación en la Escuela jugaba un papel de primer orden el dibujo, por lo que no resulta difícil encontrar entre sus egresa-

66 SATUÉ, Enric, El libro de los anuncios II. Los años de aprendizaje (1931-1939), Barcelona, Alta Fulla, 1988, p. 42.

67 José Espert obtuvo en 1933 el primer premio en el Concurso de Carteles del Círculo de Bellas Artes. VELA, Concha, Carnavales, Colección de carteles del Círculo de Bellas Artes, Madrid, Círculo de Bellas Artes, 1993, pp. 138-139.

68 Diccionario de pintores y escultores españoles del siglo XX, t. IV, Madrid, Forum Artis, 1994-2000, pp. 11261127; EGUIZÁBAL MAZA, Raúl, El cartel en España, Madrid, Cátedra, pp. 288-289. dos a excelentes pintores y dibujantes. Pero también a diseñadores de interesantes carteles y anuncios, merecedores en algún caso de figurar en la antología más exigente de artistas publicitarios de esta época comprometida con el arte nuevo ${ }^{69}$. Pero si la revista Obras resulta vanguardista por su diseño gráfico publicitario, lo fue también desde el punto de vista de la comunicación comercial, al constituir un magnífico testimonio del esfuerzo por parte de algunas empresas europeas y americanas de la época por crear una identidad visual corporativa con la que posicionarse sólidamente en el mercado. Esfuerzo en el que el arte, los artistas $\mathrm{y}$-no en último lugar- los arquitectos jugaron un papel fundamental.

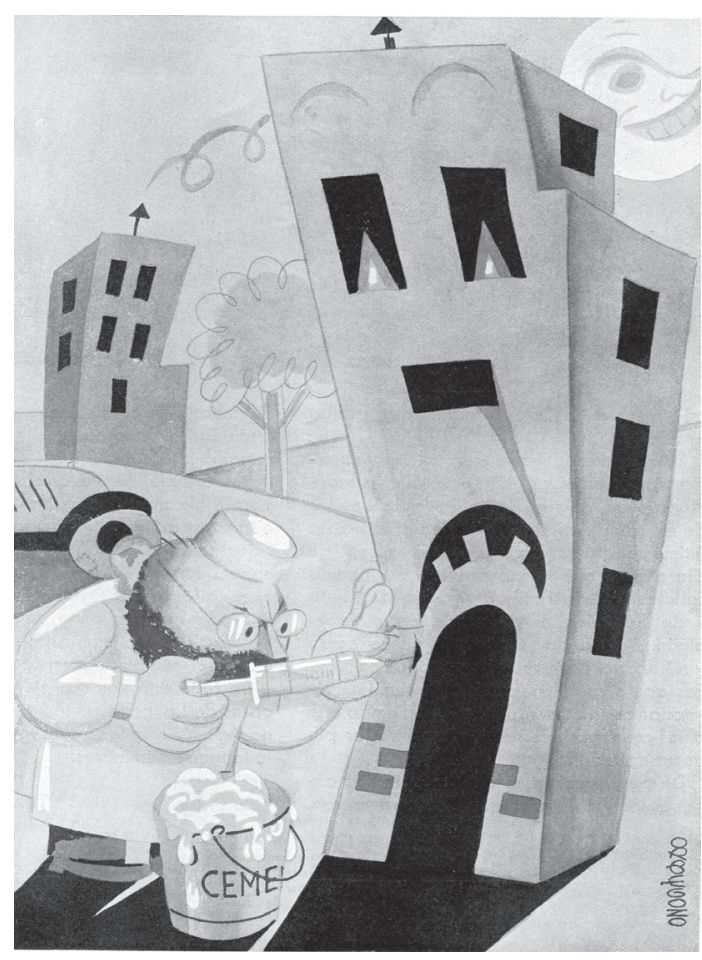

Fig. 8. Antonio Orbegozo, Ilustración para el relato de Tirso de Molina "Patología de la construcción". Obras, 17 (1933).

\footnotetext{
9 Baste señalar en este sentido los nombres de Joaquín Vaquero Palacios, Luis Moya Blanco y Eduardo Lagarde. Estos dos últimos llegaron incluso a publicar anuncios comerciales de cemento y persianas en revistas profesionales de aquellos años tan relevantes como Arquitectura o AC.
} 